\title{
LA JUDICIALIZACIÓN DE LA POLÍTICA DE LA SALUD EN MÉXICO: ¿CUÁL ES EL PAPEL DE LOS JUECES ANTE LA PANDEMIA POR COVID-19?
}

\author{
THE JUDICIALIZATION OF HEALTH POLICY IN \\ MEXICO: WHAT IS THE ROLE OF THE JUDGES IN \\ THE COVID-19 PANDEMIC?
}

\begin{abstract}
Enrique García-Tejeda*
Daniel Torres Checa**
\end{abstract}

\section{Resumen}

Las resoluciones de la Suprema Corte de Justicia de la Nación sobre el alcance del principio de relatividad y la protección ante la inacción de las autoridades administrativas, han aumentado el margen de incidencia de los jueces constitucionales en las políticas públicas. Este papel de los jueces es relevante para los estudios de derecho y de políticas públicas. Por ello, este artículo identifica y analiza tres casos de jueces federales que ordenan medidas de protección a la salud, el suministro de agua potable y un ingreso mínimo vital, de marzo a agosto de 2020. Hallamos que, a pesar de los criterios de la Suprema Corte, posiblemente los jueces no participan en el diseño de políticas públicas durante la pandemia y su papel se reduce a la reafirmación de valores sociales.

Palabras clave: Juez constitucional, derechos colectivos, deferencia judicial, derecho a la salud, diseño de políticas, marco de corrientes múltiples.

Doctor en Políticas Públicas por el Centro de Investigación y Docencia Económicas (CIDE). Profesor de la Facultad de Derecho y de la Escuela de Gobierno y Economía de la Universidad Panamericana. Línea de investigación: Derecho y Políticas Públicas. Correo electrónico: cgarcia@up.edu.mx.

** Abogado por la Universidad Panamericana y candidato a maestro en Derecho Constitucional por la Escuela Libre de Derecho. Línea de investigación: Justicia, Democracia, Derechos Humanos, División de Poderes. Correo electrónico: torrescheca25@gmail.com.

Fecha de recepción: 29 de julio de 2020.

Fecha de aceptación: 07 de julio de 2021. 


\section{Abstract}

The judicial resolutions by the Mexican Supreme Court of Justice regarding the relativity principle and protection against administrative authorities' inaction have increased the judicial faculties of constitutional judges on public policies. The role of these judges is relevant for law studies and public policy studies. In this article, we identify and analyze three cases of federal judges that order measures about health protection, water supply, and a minimum living wage from March 1st to August 31st, 2020. We found that despite the Supreme Court criteria, judges very likely do not participate in public policy design during the COVID-19 pandemic, and their role is reduced just to the reaffirmation of social values.

Keywords: Constitutional Court, Collective Rights, Judicial Deference, Right to Health, Policy Design, Multiple Streams Framework.

\section{Introducción}

Este artículo tiene como objetivo estudiar el papel de los jueces en las políticas públicas de salud en México durante la pandemia de COVID-19. Para ello, se analizan tres resoluciones de juicios de amparo y se contrasta el rol de los jueces y tribunales con el marco teórico del proceso de políticas públicas. Estos juicios examinados son aquellos que pudieron ser identificados de marzo a agosto de 2020, y cuya materia es el derecho a la salud durante la emergencia sanitaria.

El primer caso examinado data de marzo de 2020. En este juicio de amparo, un habitante de Michoacán reclama a las autoridades sanitarias la omisión de medidas de contención, prevención y detección del COVID-19 para evitar el contagio y propagación del virus. El juez concedió una suspensión del plano al quejoso para que las autoridades responsables comprueben las medidas y acciones para la protección de la salud durante la pandemia.

El segundo caso analizado es de julio de 2020. En este juicio de amparo, un habitante de San Luis Potosí reclama la inacción de las autoridades municipales para proporcionar agua potable en su domicilio y colonia. El desabasto impide al quejoso dar seguimiento a las medidas de prevención de lavado de manos establecidas por la Organización Mundial de la Salud (OMS) ante la pandemia provocada por el virus SARSCoV-2. El juez ordenó a la autoridad municipal tomar las medidas conducentes para asegurar el abastecimiento de agua en la comunidad del quejoso.

Finalmente, el juicio de amparo analizado en el caso tercero, también de julio de 2020, relata la situación de un profesor y sus dos hijos menores de edad, que se vieron 
despojados de su ingreso, sus prestaciones de salud y de seguridad social ante la pérdida de trabajo del profesor en medio de la emergencia sanitaria. El quejoso reclama el derecho a un ingreso mínimo vital para proteger la vida y la salud de su familia. El juez concedió la suspensión de plano para que las autoridades responsables dicten las medidas urgentes para garantizar el ingreso mínimo vital hasta en tanto subsiste la contingencia de salud.

Al examinar estos casos, la investigación trata de responder las siguientes preguntas: ¿los jueces federales son actores relevantes en el diseño de las políticas de salud en México? O, por el contrario, ¿su actuación está marcada por la ambigüedad y aleatoriedad para participar en un área de política pública?

Para contestar estas preguntas, se utiliza la definición de política pública ${ }^{1}$ orientada a problemas públicos. Desde esta perspectiva, la política pública está orientada a la generación de conocimiento para resolver los problemas fundamentales de la sociedad, ${ }^{2}$ donde el elemento central es una situación en la cual se considera oportuno intervenir con instrumentos y recursos públicos: impuestos, subsidios, normas jurídicas, aplicación de sanciones, entre otros. ${ }^{3}$

Las justificaciones para que el gobierno intervenga en una situación pueden ser económicas o sociales. En el primer caso, el gobierno intenta corregir un fallo de mercado; en el segundo caso, las autoridades atienden problemas como crimen, pobreza, salud, entre otros. ${ }^{4}$ El proceso que sigue el gobierno para formular políticas públicas y para cambiar la situación problemática es estudiado bajo diferentes modelos. ${ }^{5}$ Esta investigación utiliza dos modelos diferentes de este proceso de las políticas públicas: el diseño de políticas y el marco de las corrientes múltiples.

Para el modelo de diseño de políticas públicas, los elementos centrales de la formulación de la política pública son: la definición del problema público, la elección de un instrumento de política, los criterios de la evaluación de una política y un plan de acción. ${ }^{6}$ Por otra parte, en lugar de esta intervención planificada, el modelo marco de las corrientes múltiples explica la formulación de políticas públicas como resultado de un proceso aleatorio de actores y eventos. ${ }^{7}$

\footnotetext{
Esta investigación también utiliza la diferencia entre política (politics) y políticas ( $p o l i c y)$ que existe en el idioma inglés. En el primer caso, la política atiende los asuntos públicos de quienes rigen o aspiran a regir dichos asuntos. En el segundo, las políticas son las formas en que se conduce un asunto o se emplean los medios para alcanzar un fin determinado en la esfera de lo público, como es la atención de problemas públicos. Esta última definición es la utilizada en este artículo.

2 Lasswell, Harold, "The Policy Orientation”, en Lerner, Daniel y Lasswell, Harold (eds.), The Policy Sciences, Standford, Stanford University Press, 1951, p. 8.

3 Howlett, Michael et al., "From Tools to Toolkits in Policy Design Studies: the New Design Orientation Towards Policy Formulation Research", Policy \& Politics, núm. 43, vol. 2, abril de 2015, disponible en: https://www.researchgate.net/ publication/275719874_From_tools_to_toolkits_in_policy_design_studies_The_new_design_orientation_towards_policy_formulation_research.

4 Peters, B. Guy, Advanced introduction to public policy, University of Pittsburg, 2015, pp.14-17.

5 Peters, B. Guy y Zittoun, Philippe, Contemporary Approaches to Public Policy, Theories, Controversies, and Perspectives, Londres, Palgrave Macmillan, 2016, pp. 7-8.

6 Peters, B. Guy, op. cit., pp. 20-24.

7 Peters, B. Guy y Zittoun, Philippe, op. cit., p. 163.

García-Tejeda, Enrique y Torres Checa, Daniel, "La judicialización de la política de la salud en México...", Jurídica Ibero, año 6, julio-diciembre, 2021.
} 
Desde el punto de vista del derecho constitucional, en esta investigación se considera que las políticas públicas son actos de autoridad de carácter administrativo que buscan atender los problemas públicos, y que están sujetos a los principios de fundamentación y motivación establecidos en los artículos 14 y 16 de la Constitución Mexicana. Esas acciones $\mathrm{u}$ omisiones administrativas pueden ser revisadas jurisdiccionalmente, por lo que, en caso de ser controvertidas, los jueces y tribunales pueden desempeñar un papel dentro de las políticas públicas. Esta investigación indaga sobre el tipo de rol que desempeñan en el diseño.

Dentro de la literatura del derecho a la salud, la región de Latinoamérica ha generado un amplio cuerpo de investigación en el estudio del papel de los jueces en diversos países con problemática similar. El enfoque de estas investigaciones ha sido el cumplimiento del derecho a la salud mediante el litigio constitucional. ${ }^{8}$ El artículo analiza los elementos extralegales que los jueces pueden considerar en el juicio de amparo sobre esta materia. ${ }^{9}$ Estos juicios son considerados como manifestaciones individuales de la judicialización del derecho a la salud en México. ${ }^{10}$

Sobre el contenido del artículo, en la primera sección se plantea el problema del papel de los jueces en la literatura jurídica. En la segunda sección, se expone el marco teórico del diseño de las políticas públicas y el marco de las corrientes múltiples. En la tercera sección, se presenta la evidencia de las resoluciones analizadas desde los modelos de proceso de políticas públicas utilizados. En la cuarta sección, se discuten los resultados con la evidencia estudiada y, finalmente, son presentadas las conclusiones.

Respecto a los hallazgos de la investigación, la evidencia analizada permite sostener que, a pesar de la mayor participación de los jueces en políticas de salud en México, posiblemente los jueces federales no participan en el diseño de políticas públicas y su papel se reduce a la reafirmación de valores sociales frente a la pandemia por COVID-19, por lo que el marco de las corrientes explica mejor el papel de los jueces federales en las políticas públicas. En cuanto a la literatura del derecho a la salud, la escasa participación de los jueces federales frente a la pandemia es consistente con una novedosa investigación que estudia los fallos de la Suprema Corte de Justicia de la Nación en México en un periodo amplio (2011-2017). ${ }^{11}$ Ese estudio encuentra que la Suprema Corte ha perdido la oportunidad de tener una participación más activa en la política de salud, ${ }^{12}$ por lo que nuestros resultados al examinar los juicios de amparo durante la pandemia son similares.

\footnotetext{
8 Motta Ferraz, Octávio Luiz, "Health in the Courts of Latin America", Health and Human Rights, núm. 20, vol. 1, 2018, disponible en: https://www.ncbi.nlm.nih.gov/pmc/articles/PMC6039732/, pp. 67-77.

9 Cobo, Fernanda y Charvel, Sofia, "Mexican Apex Judiciary and its Multiple Interpretations: Challenges for the Constitutional Right to Health", International Journal of Constitutional Law, vol. 18, núm. 4, 2020, disponible en: https:// academic.oup.com/icon/article-abstract/18/4/1254/6077862, p. 1256.

${ }^{10}$ Ibidem, p. 1257.

11 Ibidem, p. 1254.

12 Ibidem, p. 1267. García-Tejeda, Enrique y Torres Checa, Daniel, “La judicialización de la política de la salud en México...”, Jurídica Ibero, año 6, julio-diciembre, 2021.
} 


\section{El rol de los jueces en el derecho y las políticas públicas: un problema vigente}

\section{La participación de los jueces y el uso de la deferencia administrativa}

Desde una perspectiva constitucional, existe una discusión sobre el riesgo de que un juez sustituya al órgano administrativo, que en principio le corresponde el diseño de políticas públicas. ${ }^{13}$ Si bien el sistema de pesos y contrapesos configura las facultades de los poderes tradicionales, los jueces pueden verse expuestos a decidir sobre materias que escapan a su experiencia e invadir la competencia de autoridades democráticamente elegidas para atender una problemática social. ${ }^{14}$

Para evitar esa posible transgresión de facultades, se ha planteado la existencia de controles de autocontención y deferencia administrativa. En términos generales, la deferencia es el respeto que otorga un juez a la decisión de otro poder, ya sea al legislativo, al ejecutivo o a algún órgano constitucional autónomo, reconociendo su autonomía política o técnica para emitir cierta regulación:

[L]a deferencia deriva de una situación en la que un segundo tomador de decisiones acepta o adopta el criterio de un primer tomador de decisiones — por ejemplo, el juez hacia el legislador o la autoridad administrativa- - La aceptación del criterio del primer tomador de decisiones se justifica en la condescendencia o el respeto que se tiene a la institución y, por ende, a las decisiones tomadas por ésta. ${ }^{15}$

Esta deferencia no es una renuncia del deber del juez constitucional de controlar constitucionalmente leyes, actos u omisiones. Representa la decisión del juez de adoptar el criterio de política pública que las autoridades competentes establezcan, ya que considera que dichas autoridades se encuentran en mejor posición para la formulación de las políticas.

La discusión del papel de los jueces en las políticas públicas es relevante en la literatura de derecho administrativo de diferentes países. En Estados Unidos de América

\footnotetext{
${ }_{13}$ Celis Quintal, Marcos Alejandro, "El papel del Poder Judicial en el esquema de división de poderes de las entidades federativas", Biblioteca del Instituto de Investigaciones Jurídicas de la UNAM, UNAM, Instituto de Investigaciones Jurídicas, 2005, disponible en: https://archivos.juridicas.unam.mx/www/bjv/libros/4/1784/18.pdf, pp. 289-304.

${ }^{14}$ Martínez Estay, José Ignacio, “Auto-Restricción, Deferencia y Margen de Apreciación. Breve Análisis de sus orígenes y de su desarrollo", Centro de Estudios Constitucionales de Chile, Universidad de Talca, Chile, año 12, núm. 1, 2014, disponible en: https://scielo.conicyt.cl/pdf/estconst/v12n1/art09.pdf, pp. 365-395. Véase también: Véase la importancia del rol que juega el Poder ejecutivo y legislativo con los cuerpos que no son democráticamente electos, como la judicatura, en: Leigh, Tara, "Book Review: The Supreme Court's Legytmacy Dilemma", Harvard Law Review, 2019, disponible en: https://harvardlawreview.org/wp-content/uploads/2019/06/2240-2276_Online.pdf.

15 Badillo Juárez, María José, "La deferencia de los tribunales especializados en competencia económica, telecomunicaciones y radiodifusión”, Tesis de licenciatura, México, CIDE, 2018, disponible en: http://hdl.handle.net/11651/2687, p. 97.
} 
(EE. UU.), el caso Chevron USA vs. Natural Resources Defense Council de 1984 sentó las bases para otorgar una deferencia administrativa hacia la administración pública y sus agencias, las cuales tienen una mayor pericia técnica en política pública que otras autoridades.

Bajo este principio, los jueces se limitan a analizar normas administrativas para estudiar la ambigüedad y razonabilidad de la política pública, ${ }^{16}$ pero dejan a la autoridad administrativa la decisión técnica si no existe ambigüedad jurídica y la intervención es razonable. ${ }^{17}$ Este principio fue reforzado con los casos de U.S. vs. Mead Corp (2001), y Winter vs. Natural Resources Defense Council (2008).

En Latinoamérica, las investigaciones señalan a la Corte Constitucional Colombiana como un actor importante en la formulación y desarrollo en las políticas públicas. La doctrina ha clasificado su actuación a partir de cuatro escenarios no excluyentes, a saber: a) jugador con poder de veto; b) jugador proactivo; c) árbitro imparcial, y d) representante de la sociedad. ${ }^{18}$ Principalmente, la literatura identifica a la Corte Colombiana como jugador con poder de veto — es decir, con la posibilidad que tiene la Corte para contravenir leyes, actos u omisiones que resulten contrarias al orden constitucional-, y como representante de la sociedad - esto es, como vocera y defensora de pueblos y colectividades - Bajo estas perspectivas, para varios autores su relevancia como actor de política pública es esencial, toda vez que tiene la posibilidad de justiciar derechos colectivos, económicos y sociales y, a través de sus fallos, puede reconfigurar el orden institucional. ${ }^{19}$

En el caso de México, en 2018 y 2019, la reinterpretación del principio de relatividad en las sentencias de los juicios de amparo ${ }^{20}$ y la protección cautelar de los quejosos ante la inacción de las autoridades administrativas ${ }^{21}$ por parte de la Suprema Corte de Justicia de la Nación, pueden propiciar una mayor participación de los tribunales al instrumentar, analizar y evaluar políticas públicas. Con el objetivo de contribuir a esa línea de investigación sobre el análisis de elementos extralegales en el juicio de amparo por parte de los jueces constitucionales, aquí se examina su participación en la formulación de las políticas de salud, en el contexto pandémico provocado por el virus SARS-CoV-2 en México.

16 Franco Talamantes, Amadeo, "Neil Gorsuch y el futuro del derecho administrativo", Revista Nexos, 10 de mayo de 2017, disponible en: https://eljuegodelacorte.nexos.com.mx/? $p=6580 \#$ ftn6.

17 Ventura Rodríguez, Manuel Enrique, "La deferencia a favor de las Administraciones públicas en el Derecho Administrativo Contemporáneo", Estudios Jurídicos sobre Administración Pública, Posgrado de la Universidad Nacional Autónoma de México, México, 2012, disponible en: http://derecho.posgrado.unam.mx/congresos/ivci_vmda/ponencias/ManuelVentura.pdf.

18 Jaramillo, Luis Eduardo y Pachón, Mónica, “Control de constitucionalidad abstracto y sus implicaciones en las políticas públicas: el caso de la descentralización fiscal en Colombia", Universidad de los Andes, Escuela de Gobierno Alberto Lleras Camargo, Bogotá, julio 2019, disponible en: https://egob.uniandes.edu.co/images/books/DT/DT-64.pdf.

19 Idem.

20 Tesis 1a. XXU/2018, Seminario Judicial de la Federación y su Gaceta, Décima Época, libro 52, marzo de 2018, p. 1101; bajo el rubro: Principio De Relatividad. Su Reinterpretación A Partir De La Reforma Constitucional De 10 De JUNIO DE 2011.

${ }_{21}$ Tesis 1a./J. 70/2019, Seminario Judicial de la Federación y su Gaceta, Décima Época, libro 73, diciembre de 2019, p. 286; bajo el rubro: Suspensión. La Naturaleza Omisiva Del Acto Reclamado No Impide Su Procedencia. 


\section{La participación de los jueces en el derecho a la salud}

La participación de los tribunales en las políticas públicas es un tópico de interés en el derecho a la salud. ${ }^{22}$ En esta literatura, los estudios analizan la forma de la intervención judicial en un escenario de recursos limitados, desde una actitud de deferencia administrativa hasta una participación más sustantiva. ${ }^{23}$ Por otra parte, estas investigaciones consideran que los resultados en las políticas de salud probablemente dependan de las diferentes características de los países y las regiones. ${ }^{24}$

La discusión académica del rol de los jueces es más intensa en Latinoamérica debido al gran número de litigios en la región y a una mayor disposición de los jueces para cumplir con el derecho a la salud. ${ }^{25}$ En contraste, los estudios sobre Reino Unido, Estados Unidos y los países escandinavos, han encontrado que los arreglos institucionales y la formulación de políticas de salud en esos países inhiben el litigio del tema. ${ }^{26}$ En el caso de sistemas de alta calidad, como en Reino Unido, no existe una legislación expresa al derecho a la salud, por lo que puede no ser un factor determinante para su adecuado cumplimiento en estos países. ${ }^{27}$

En Brasil y Colombia, el gran número de litigios de protección a la salud llevó a los tribunales a emitir sentencias para compeler a los formuladores de políticas a organizar los servicios de salud entre los agentes del sector: autoridades gubernamentales, profesionales de la medicina, organizaciones de la sociedad civil y compañías de seguros de salud. ${ }^{28}$

En el caso de Brasil, se ha discutido sobre las consecuencias negativas de la judicialización en la equidad de la protección a la salud. ${ }^{29}$ Los individuos que recurren a la protección judicial obtienen una tasa promedio de éxito del 70 al 80\% entre diferentes instancias, ${ }^{30}$ sin embargo, esta protección no es generalizada. Los fallos protegen sólo a los individuos que acuden a los tribunales, y su efecto sobre las autoridades administrativas responsables del sector salud es, cuando menos, ambiguo. ${ }^{31}$

Este es el caso de algunos medicamentos suministrados por el gobierno brasileño, ya que están incluidos en las listas de tratamiento, pero los pacientes no los reciben si no

\footnotetext{
22 Yamin, Alicia y Gloppen, Siri (coords.), Litigating Health Rights. Can Courts Bring More Justice to Health?, Massachusetts, Harvard University Press, 2011.

${ }^{23}$ Motta Ferraz, Octávio Luiz, op. cit., pp. 68 y 71.

${ }^{24}$ Ibidem, p. 70.

${ }^{25}$ Ibidem, p. 68

${ }^{26}$ Lamprea, Everaldo, "The Judicialization of Health Care: A Global South Perspective", Annual Review of Law and Social Science, núm. 13, 2017, p. 182

27 Motta Ferraz, Octávio Luiz, op. cit., p. 76.

${ }^{28}$ Lamprea, Everaldo, op. cit., p. 18.4

29 Cobo, Fernanda et al., "La judicialización del derecho a la protección de la salud desde la óptica de los actores clave", $S a$ lud Pública de México, núm. 63, vol. 2, marzo-abril de 2021, p. 309.

${ }^{30}$ Hoffmann, Florian y Bentes, Fernando R.N.M., Accountability for Social and Economic Rights in Brazil, Cambridge, Cambridge University Press, 2008

${ }^{31}$ Landau, David, "The Reality of Social Rights Enforcement”, Harvard International Law Journal, núm. 53, 2012, p. 230. 
acuden a un tribunal. El litigio ante estas instituciones se ha convertido en un reemplazo de las autoridades administrativas. ${ }^{32}$ No obstante, algunas investigaciones enfocadas en las regiones del sur de Brasil argumentan que los litigios no afectan la equidad del acceso a la salud, sino que son mecanismos de participación y rendición de cuentas para la administración pública, y que contribuyen al avance de la cobertura universal en dicho país. $^{33}$

Por lo que respecta a Colombia, este país fue una de las naciones en Latinoamérica con el mayor número de casos litigados en 2007 y 2008, con 107, 238 y 142,957 juicios respectivamente (tutelas). ${ }^{34}$ Esta situación llevó a la Corte Constitucional a reconfigurar su sistema de salud. ${ }^{35}$ Destaca la sentencia T-760/2008, la cual resolvió 22 tutelas que reflejaban los problemas sistémicos del sector salud, y ordenó una transformación general del propio sistema. ${ }^{36}$

La sentencia T-760 ordenó corregir las fallas de regulación para informar, orientar y acompañar a las personas en los cuidados de su salud mediante un aumento en la cobertura territorial y en la actualización, homologación e información completa a los pacientes de los planes de salud. ${ }^{37}$ La Corte Constitucional no estableció el contenido sustantivo de los planes de salud, sino que estableció las bases de un diálogo amplio sobre su contenido entre los actores relevantes del sector y los beneficiarios de las políticas. ${ }^{38}$ A pesar de las reticencias iniciales de las administraciones públicas (2002-2010 y 2010-2018), quienes crearon decretos ejecutivos en estados de emergencia, la Corte declaró estas medidas como inconstitucionales y logró el cumplimiento de su decisión con el apoyo de sindicatos, profesionales de la salud e iglesias, entre otros actores. ${ }^{39}$

En México son escasos los estudios sobre judicialización de derechos de protección a la salud, ya que ha sido de los pocos países en la región en donde el número de litigios es reducido. Algunas investigaciones señalan que puede deberse al reducido acceso a la justicia por los altos costos del juicio de amparo. ${ }^{40}$ No obstante, en los próximos años pueden surgir cada vez más investigaciones, ya que los actores clave consideran que la judicialización es un fenómeno ineludible en el sector salud en México. ${ }^{41}$

\footnotetext{
32 Ibidem, p. 232.

33 Biehl, João et al., "The Judicialization of Health and the Quest for State Accountability: Evidence from 1,262 Lawsuits for Access to Medicines in Southern Brazil”, Health and Human Rights, núm. 18, vol. 1, 2016, pp. 216 y 218.

${ }^{34}$ Parra-Vera, Oscar y Yamin, Alicia, "La sentencia T-760 de 2008, su implementación e impacto: Retos y oportunidades para la justicia dialógica”, Tratado de derecho a la salud, Argentina, Abeledo Perrot, 2013, p. 2605.

35 Cobo, Fernanda et al., op. cit., p. 309.

${ }^{36}$ Parra-Vera, Oscar y Yamin, Alicia, op. cit., pp. 2592 y 2611.

${ }^{37}$ Arrieta-Gomez, Aquiles Ignacio, "Realizing the Fundamental Right to Health Through Litigation: the Colombian Case", Health and Human Rights, núm. 20, vol. 1, 2018, pp. 143. Véase también: Parra-Vera, Oscar y Yamin, Alicia, op. cit., p. 2592.

38 Ibidem, pp. 2615, 2645 y 2647.

39 Arrieta-Gomez, Aquiles Ignacio, op. cit., p. 138.

${ }^{40}$ Cobo, Fernanda y Charvel, Sofía, op. cit., pp. 1256-1257.

${ }^{41}$ Cobo, Fernanda et al., op. cit., p. 308.
} 
Un interesante estudio identificó y analizó 22 sentencias de la Suprema Corte de Justicia de la Nación, de agosto de 2011 a junio de 2017, sobre el derecho constitucional a la salud. ${ }^{42}$ En esta investigación se encontró que la Suprema Corte ha perdido la oportunidad de gobernar de manera proactiva en la protección a la salud. Aunque ha sido coherente en la definición del derecho, ha sido inconsistente en los principios y en el análisis de argumentos extra-legales orientados a la política pública (policy oriented way). ${ }^{43}$

\section{La participación de los jueces desde los estudios de políticas públicas}

En la literatura de políticas públicas, hay una discusión sobre el grado de intervención de los jueces y el rol que desempeñan en una amplia variedad de temáticas. En el estudio del proceso de formulación de políticas, los jueces y tribunales pueden desempeñar diferentes roles en sus etapas. Estos individuos y órganos colegiados pueden participar en: la agenda pública, en la formulación de una política, en su implementación o en su evaluación..$^{44}$

En un libro clásico del tema, Tate y Vallinder hacen una crónica de casos que expanden los límites tradicionales del poder judicial a las políticas públicas en países dentro de Europa, América Latina y África. ${ }^{45}$ Para el caso de Estados Unidos, McKeever analiza las decisiones de la Suprema Corte en problemas públicos de aquel país, como el aborto, la pena de muerte, la acción afirmativa para las minorías, entre otros. ${ }^{46}$ Estos autores sostienen que este aumento de la actividad judicial en las políticas públicas corresponde a una renuncia de las legislaturas para intervenir en los problemas públicos, debido a la complejidad y número de asuntos. ${ }^{47}$

Para autores como Rabkin, en Estados Unidos, los jueces tienen un rol activo en las políticas públicas, que afecta la consistencia y orden de la Administración Pública. Para sostener su argumento, el autor se basa en casos de intervención judicial en la Oficina de los Derechos Civiles, la Administración de Alimentos y Medicamentos (FDA, por sus siglas en inglés) y el Departamento de Seguridad y Salud Ocupacional..$^{48}$ En la misma línea argumentativa, para el Juez estadounidense Robert Bork, la práctica judicial que pugna por legislar, en lugar de interpretar las leyes, se intensificó a partir del siglo XX. ${ }^{49}$ Ambos autores consideran que los jueces buscan activamente una mayor injerencia.

$\overline{42}$ Cobo, Fernanda y Charvel, Sofía, op. cit., p. 1254.

43 Ibidem, p. 1267.

${ }^{44}$ La división por etapas del proceso de políticas públicas es un análisis clásico en el área. Aunque en las últimas décadas hay otros modelos de análisis del proceso de políticas, aquí solo se hace referencia al modelo tradicional de análisis por etapas.

45 Tale, Neal y Vallinder, Torbjorn, The Global Expansion of Judicial Power, Nueva York, New York University Press, 1997.

${ }^{46}$ McKeever, Robert J., Raw Judicial Power?: The Supreme Court and American Society, Manchester, Manchester University Press, 1993.

47 Baird, Vanessa y Jacobi, Tonja, "Judicial Agenda Setting Through Signaling and Strategic Litigant Responses”, Washington University Journal of Law \& Policy, núm. 29, 2009, p. 216.

48 Rabkin, Jeremy A., Judicial Compulsions: How Public Law Distorts Public Policy, New York, Basic Books, 1989.

49 Bork, Robert H., The Tempting of America, Nueva York, Free Press, 1997. 
En un influyente artículo de 2009, Baird y Jacobi sostienen que las teorías de expansión y de activismo judicial no describen adecuadamente el papel de los jueces en las políticas públicas. Los autores presentan evidencia sobre la configuración de la agenda de la Suprema Corte de Estados Unidos en las políticas públicas. Sus hallazgos muestran que los jueces mandan señales sobre los asuntos que desean analizar a los litigantes, por lo que los tribunales dependen de la actuación de los abogados para construir su agenda en las políticas públicas. ${ }^{50}$ Por lo tanto, los litigantes desempeñan un papel importante en esta relación estratégica: son considerados "emprendedores de políticas" (policy entrepreneurs) que interpretan las señales que los jueces emiten y a estos les permiten influir en las políticas. ${ }^{51}$

Estas discusiones de la literatura sobre el papel de los jueces en las políticas públicas son actualmente relevantes para México. A partir de la reforma constitucional de junio de 2011, la Suprema Corte de Justicia de la Nación ha emitido diversas resoluciones encaminadas a proteger efectivamente los derechos colectivos, ${ }^{52}$ así como a proteger a los particulares ante la inacción de la autoridad administrativa. ${ }^{53}$ Desde esta perspectiva, tanto la reforma como los criterios derivados de ella ampliaron —al menos teóricamente- el margen de incidencia de los jueces en los procesos de formulación de políticas públicas.

La emergencia sanitaria provocada por el COVID-19 ha materializado la protección judicial de derechos colectivos ante la inacción de la autoridad administrativa. Los casos presentados en este documento sirven para esclarecer el papel de los jueces en el proceso de las políticas públicas. Con este objetivo, en la siguiente sección son presentados los marcos teóricos que sirven como fundamento de la metodología de análisis para los casos judiciales presentados.

\section{El marco teórico para el análisis de los casos presentados}

\section{El diseño de las políticas públicas (policy design)}

El diseño de políticas públicas postula que una intervención gubernamental proviene de un intento deliberado del gobierno para entender las causas de un problema, seleccionar

${ }_{50}$ Baird, Vanessa y Jacobi, Tonja, op. cit. p. 17.

${ }^{51}$ Ibidem, p. 238.

52 Tesis 1a. XXU/2018, Seminario Judicial de la Federación y su Gaceta, Décima Época, libro 52, marzo de 2018, p. 1101; bajo el rubro: Principio De Relatividad. Su Reinterpretación A Partir De La Reforma Constitucional De 10 De JUNIO DE 2011.

53 Tesis 1a./J. 70/2019, Seminario Judicial de la Federación y su Gaceta, Décima Época, libro 73, diciembre de 2019, p.286; bajo el rubro: Suspensión. La Naturaleza Omisiva Del Acto Reclamado No Impide Su Procedencia. 
una intervención determinada dentro de un conjunto de instrumentos gubernamentales disponibles y esperar alcanzar metas previamente establecidas. ${ }^{54}$

Este diseño de políticas públicas surgió en los años 80 y 90 del siglo pasado, y ha tomado impulso recientemente en investigaciones de este rubro en una amplia variedad de países y ámbitos de aplicación. ${ }^{55} \mathrm{El}$ enfoque está fuertemente relacionado con el análisis por etapas de las políticas públicas, el cual es un modelo heurístico para estudiar diferentes momentos del proceso de formulación de políticas, sin que exista un orden o separación real, ya que las etapas se presentan en diferente jerarquía y las divisiones entre ellas no son claras. ${ }^{56}$

Uno de los usos más importantes del modelo de políticas públicas por etapas es que permite un punto de inicio para el diseño de políticas por parte de los analistas. ${ }^{57}$ Las obras dirigidas a éstos intentan ser una guía para la definición de un problema público, la selección de un instrumento, el establecimiento de metas y objetivos, así como criterios de valoración y, finalmente, la implementación y la evaluación de la política diseñada. ${ }^{58}$

Cada una de las etapas del diseño de políticas públicas posee una amplia literatura. En el caso de los instrumentos de políticas públicas, los estudios datan de 1964, cuando Kirschen enlistó 64 de ellos. ${ }^{59}$ Un par de décadas más tarde, Hood propuso clasificar los instrumentos en información, autoridad, dinero y organización (NATO, por sus siglas en inglés) ${ }^{60}$ Las clasificaciones más actuales proponen una división entre instrumentos coercitivos y no coercitivos, ${ }^{61}$ e instrumentos económicos, legales, persuasivos y genéricos. ${ }^{62}$

Con el desarrollo del estudio de las políticas públicas, han surgido marcos distintos al enfoque tradicional de análisis por etapas y al diseño de aquéllas. Estos enfoques han criticado la falta de realidad de los supuestos de racionalidad del enfoque clásico de formulación de políticas, y han propuesto alternativas para enriquecer el estudio del proceso de su elaboración. ${ }^{63}$ Uno de los enfoques alternativos con una agenda de investigación activa es el marco de corrientes múltiples (multiple streams framework). ${ }^{64}$

\footnotetext{
${ }^{54}$ Howlett, Michael et al., op. cit.

55 Ibidem, p. 9.

56 Cairney, Paul, Understanding Public Policy, Londres, Red Globe Press, 2012, p. 41.

57 Idem.

${ }_{58}$ Bardach, Eugene, Los ocho pasos para el análisis de Políticas Públicas, un manual para la práctica, México, CIDE, 2001.

59 Kirschen, Etienne Said, Economic Policy in Our Time, Ámsterdam, North-Holland Publishing, 1964.

${ }^{60}$ Hood, Christopher, The Tools of Government, Nueva Jersey, Chatham House Publishers, 1984.

${ }^{61}$ Macdonald, Douglas, "Coerciveness and the Selection of Environmental Policy Instruments", Canadian Public Administration, núm. 44, vol. 2, 2001, pp. 161-187.

62 Peters, B. Guy, op. cit., p. 103.

${ }_{63}$ Zahariadis, Nikolaos, Bounded Rationality and Garbage Can Models of Policy-Making, Londres, Palgrave Macmillan, 2016, p. 156.

${ }^{64}$ Cairney, Paul y Jones, Michael D., "Kingdon's Multiple Streams Approach: What Is the Empirical Impact of this Universal Theory?”, Policy Studies Journal, núm. 44, vol. 1, 2016, pp. 37-58. 


\section{El marco de las corrientes múltiples (multiple streams framework)}

El marco de las corrientes múltiples postula que las políticas públicas surgen en condiciones de ambigüedad y aleatoriedad, donde la capacidad de procesamiento de los formuladores de políticas públicas es limitada. Esta última característica va acompañada de un tiempo limitado, por lo que "el enfoque de las corrientes múltiples comparte con el concepto de racionalidad limitada de [Herbet] Simon... el orden en que se consideran las soluciones afecta profundamente el resultado de la decisión" ${ }^{65}$

Este marco de análisis propone que el propio proceso de políticas públicas afecta el contenido de la intervención gubernamental, ya que las limitaciones prácticas de las organizaciones y de la racionalidad de los individuos impiden soluciones óptimas. ${ }^{66}$ Este enfoque de corrientes múltiples no rechaza los modelos racionales de formulación de políticas, sino que está construido para analizar situaciones no explicadas por los modelos racionales de análisis, así como para contar con un modelo más cercano a la formulación real de las políticas: busca ser un complemento del modelo clásico de análisis.

A diferencia del diseño de políticas públicas, donde el formulador de políticas define un problema público y elige un instrumento acorde a dicha definición del problema, en el marco de las corrientes múltiples la generación de soluciones atiende principalmente a los valores de los actores. Como lo establece Sabatier: "En forma similar, las personas generan soluciones no necesariamente porque han identificado un problema en particular, sino porque la solución resuelve un problema que se amolda a sus valores, creencias o bienestar potencial". ${ }^{67}$

Esta teoría del proceso de políticas ha tenido una mayor aplicación en la definición de la agenda de las políticas públicas (Kingdon, 1995), ${ }^{68}$ sin embargo, el alcance del marco de las corrientes múltiples es más amplio y puede ser aplicado en otras etapas del análisis, o en las situaciones de ambigüedad de los problemas públicos y de sus posibles soluciones, ${ }^{69}$ en las cuales los participantes enfrentan limitaciones en el tiempo y sus decisiones reflejan la reafirmación de valores sociales, más que un análisis del problema público y su conexión con la solución. ${ }^{70}$

Este puede ser el caso de los tribunales en México y el papel que desempeñan en las políticas de salud frente a la pandemia. La ambigüedad de la norma administrativa fundamenta la intervención de los jueces cuando no es utilizado el principio de deferencia judicial, ya que para autores como Knott, los tribunales pueden alterar el significado de

\footnotetext{
${ }_{65}$ Sabatier, Paul A., Teorias del proceso de las políticas públicas, Buenos Aires, Westview Press, 2010, p. 72.

${ }^{66}$ Zahariadis, Nikolaos, op. cit, p. 157.

${ }^{67}$ Sabatier, Paul A. op.cit. p. 87.

${ }_{68}$ Véase Kingdon, John, Agendas, Alternatives and Public Policies, Nueva York, Harper Collins, 1995, citado en Cairney, Paul y Jones, Michael D., "Kingdon's Multiple Streams Approach: What Is the Empirical Impact of this Universal Theory?", Policy Studies Journal, núm. 44, vol. 1, 2016.

${ }^{69}$ Zahariadis, Nikolaos, op. cit, p. 167.

70 Ibidem, p. 159. García-Tejeda, Enrique y Torres Checa, Daniel, “La judicialización de la política de la salud en México...”, Jurídica Ibero, año 6, julio-diciembre, 2021.
} 
una ley mediante la interpretación, por lo que sus resoluciones pueden ser un cambio en la política pública, aunque sean eventos en una secuencia. ${ }^{71}$

En los casos analizados en este artículo, se estudia si los jueces consideran alternativas de soluciones al problema público que origina la violación de los derechos colectivos, o si los jueces emiten sus resoluciones como reafirmación de valores sociales, más que un análisis de problema público. Este análisis permite clarificar el papel de los jueces en las políticas públicas bajo los modelos teóricos presentados en esta sección.

\section{Metodología de análisis y selección de casos}

La investigación toma tres estudios de caso como evidencia para aplicar los marcos teóricos expuestos de política pública: el diseño de políticas públicas y el marco de las corrientes múltiples. Se analiza la actuación de los jueces en la emergencia sanitaria del COVID-19 para ordenar medidas de protección a la salud, asegurar el suministro de agua potable y establecer un ingreso mínimo vital frente a la emergencia sanitaria en los estados de Michoacán, San Luis Potosí y Veracruz.

Estos casos fueron seleccionados por dos razones sustanciales:

1. Las medidas tomadas por la administración en materia de salud generan efectos colectivos, externalidades positivas o bienes públicos con características de no rivalidad y no exclusión. En otras palabras, una intervención exitosa ordenada por el juez para la protección de un individuo puede simultáneamente solucionar un problema público de salud en la comunidad: por ejemplo, la prevención de enfermedades, la minimización de costos en la salud, la inmunización de una población, entre otros.

2. Las resoluciones de los tribunales en los casos estudiados ordenan una intervención activa de la administración pública que hasta entonces había permanecido inactiva, por lo que, ante la resolución de los jueces, las autoridades que conforman la administración pública están obligadas a actuar.

Estas características cumplen con la definición de política pública utilizada en esta investigación: una intervención gubernamental con el propósito de atender un problema social, como lo es la salud pública. ${ }^{72}$ Los casos seleccionados también cumplen con los criterios establecidos en los trabajos coordinados por Yamin y Gloppen sobre Argentina, Brasil, Colombia, Costa Rica, India y Sudáfrica. En su libro La lucha por los derechos de la salud, el corpus de los casos analizados está basado en litigios que reclaman la protección de un derecho constitucional a la salud, demandan el acceso a instalaciones, bienes

${ }_{71}$ Knott, Jack H., "Policy Change and Deregulation: Explaining Differences in Legislative Outcomes", Policy Currents, núm. 3, vol. 1, 1993, pp. 6-7.

72 Dunn, William N., Public Policy Analysis, Estados Unidos, Routledge, 2015. Véase también: Merino, Mauricio, Politicas públicas. Ensayo sobre la intervención del Estado en la solución de problemas públicos, CIDE, México, 2013. 
o servicios, o condiciones previas para el cuidado de la salud. ${ }^{73}$ Además, en nuestro mejor conocimiento, los juicios de amparo examinados en la siguiente sección corresponden a las sentencias que pudieron ser identificadas sobre la protección de derechos de la salud frente al Covid-19 dentro del periodo analizado (marzo a agosto de 2020).

En cuanto al problema de investigación sobre el papel de los jueces, el primer supuesto del trabajo es que si un juez ordena la protección de un derecho colectivo de un particular, mediante la definición de un problema público o la selección de un instrumento entre varias alternativas, su resolución incidirá en el resultado de la política pública, ya que tendrá efectos generales en el problema de salud pública. Por tanto, los jueces participan en el diseño de las políticas de salud durante la epidemia por COVID-19.

Un supuesto diferente es que si el papel de los tribunales se origina en un contexto de ambigüedad y aleatoriedad, donde los jueces resuelven conforme a las peticiones de los particulares o reafirman valores sociales, más que un análisis independiente del problema público, su participación en el proceso de políticas depende más de actores extrajudiciales y de aleatoriedad.

Finalmente, se presenta el análisis de un caso paradigmático: el de Mini Numa, el cual estableció la protección de los derechos colectivos a la salud de una comunidad de Guerrero, mediante la orden judicial de construir un centro de salud. Este caso no fue resuelto durante la emergencia sanitaria del COVID-19, sin embargo, es incluido para fines de comparación de los casos analizados durante la pandemia.

\section{Las resoluciones de los jueces federales en la época del COVID-19}

\section{El caso de Michoacán contra la inacción de las autoridades de salud frente al coviD-19}

El 13 de marzo de 2020, un habitante de Michoacán presentó una demanda de amparo. El quejoso reclamaba a las autoridades federales sanitarias la omisión de emitir medidas y acciones sanitarias de contención, prevención y detección, para evitar el contagio y propagación del virus en territorio mexicano.

En su demanda, el quejoso menciona que se encuentra en tratamientos médicos relacionados con infección de vías respiratorias y baja en sus defensas. En ese contexto, argumenta que la falta de medidas preventivas se traducirá en la propagación del virus que, a su vez, terminaría por afectar gravemente su derecho a la salud y a la vida.

La protección efectiva del derecho a la salud del quejoso tiene una dimensión colectiva, y en casos como el estudiado, los efectos no pueden limitarse a la suspensión

\footnotetext{
73 Yamin, Alicia y Gloppen, Siri, op. cit., capítulo introductorio. García-Tejeda, Enrique y Torres Checa, Daniel, “La judicialización de la política de la salud en México...”, Jurídica Ibero, año 6, julio-diciembre, 2021.
} 
solicitada al demandante, lo que significa que las decisiones del juez impactarían irremediablemente en la protección de la sociedad.

Por otra parte, el juez expresamente menciona que la suspensión no pretende crear una política pública y, en un gesto de deferencia judicial, reconoce que deben ser las autoridades epidemiológicas quienes determinen las acciones que deben seguirse. La sentencia incidental textualmente refiere:

debe dejarse en claro que esta medida cautelar en modo alguno implica crear una política pública de salud, sino que únicamente se trata de que se cumplan las que ya están establecidas en la Ley General de Salud; esta última afirmación se sustenta en la deferencia que este órgano de control constitucional tiene con las autoridades responsables, quienes en principio están en mejor posición para determinar cuáles son las medidas adecuadas para alcanzar la plena realización de los derechos sociales... ${ }^{74}$

Así, el Juez Séptimo de Distrito en el Estado de Michoacán concedió una suspensión de plano al quejoso, para efectos de que las autoridades responsables "comprueben las medidas preventivas y acciones que han efectuado, para detectar las personas infectadas con el virus COVID-19, para garantizar la vida e integridad del peticionario de amparo". ${ }^{75}$

Es cierto que los efectos del incidente no pueden circunscribirse únicamente al quejoso, lo que puede ser conflictivo con el principio de relatividad. Sin embargo, como se ha señalado, a partir de la reforma de junio de 2011, la Suprema Corte de Justicia de la Nación reinterpretó el principio, reconociendo que "si se mantuviera una interpretación estricta del principio de relatividad, en el sentido de que la concesión del amparo nunca puede suponer algún tipo de beneficio respecto de terceros ajenos al juicio, en la mayoría de los casos sería muy complicado proteger este tipo de derechos - colectivos - en el marco del juicio de amparo". ${ }^{76}$ De esta forma, el marco jurídico actual permite que la protección del quejoso implique, indirectamente y de manera eventual, el beneficio a terceros ajenos a la controversia constitucional. ${ }^{77}$

Aunque el juez otorgó una deferencia a la administración pública, el caso ilustra la fuerza potencial que tiene el Juez Constitucional y sus resoluciones, cuyos efectos podrían cuestionar, e incluso revertir la articulación y el curso de una política pública, en provecho del quejoso, tanto en su esfera individual como en las circunstancias especiales que rodean su ámbito de protección como miembro de una colectividad.

\footnotetext{
74 Juicio de amparo 282/2020, suspensión de fecha 17 de marzo de 2020, emitido por el Juez Séptimo de Distrito en el Estado de Michoacán, p. 28.

75 Juicio de amparo 282/2020, suspensión de fecha 17 de marzo de 2020, emitido por el Juez Séptimo de Distrito en el Estado de Michoacán, p. 14.

76 Tesis 1a. XXU/2018, Seminario Judicial de la Federación y su Gaceta, Décima Época, libro 52, marzo de 2018, p. 1101; bajo el rubro: Principio De Relatividad. Su Reinterpretación A Partir De La Reforma Constitucional De 10 De JUNIO DE 2011.

${ }^{77}$ Idem.
}

García-Tejeda, Enrique y Torres Checa, Daniel, “La judicialización de la política de la salud en México...”, Jurídica Ibero, año 6, julio-diciembre, 2021. 


\section{El caso de la Colonia "Los Limones" en San Luis Potosí contra el desabasto de agua que impide seguir las recomendaciones de lavado de manos}

En la comunidad "Los Limones”, en San Luis Potosí, existe un fuerte desabasto de agua. En el contexto de la epidemia por COVID-19, lavarse las manos es una medida sanitaria elemental y una de las principales medidas de prevención ante la enfermedad.

Un habitante de la comunidad presentó, el 21 de julio de 2020, un juicio de amparo en el que reclamó al Organismo Intermunicipal Metropolitano de Agua Potable, Alcantarillado, Saneamiento y Servicios Conexos de los Municipios de Cerro de San Pedro, San Luis Potosí, "la omisión de proporcionar los servicios de suministro de agua potable para dar seguimiento a las medidas de prevención establecida por la Organización Mundial de la Salud... y la omisión de proporcionar servicios de suministro de agua de forma permanente a través de la red de agua potable y las consecuencias de ello". ${ }^{78}$

El Estado mexicano está obligado constitucionalmente a garantizar el derecho humano al agua y al saneamiento, y el desabastecimiento prolongado provoca, por sí mismo, una violación constitucional. Sin embargo, en el contexto de la pandemia, la falta de agua tiene una estrecha vinculación con el derecho a la salud y a la vida. Es en términos de estos derechos que el Juez Cuarto de Distrito de San Luis Potosí concedió una suspensión de plano a efecto de que "las autoridades señaladas como responsables tomen las medidas conducentes para el abastecimiento de uso personal y doméstico permanente de agua potable". ${ }^{79}$

De forma semejante a la resolución del caso Michoacán, el juez actuó con deferencia ante la administración municipal: obligó a dicha autoridad a tomar las medidas conducentes para el abastecimiento, sin mencionar cuáles son dichos instrumentos, por lo que se reconoce un campo de discreción a la administración pública. Por otra parte, la resolución consiste en una suspensión con efectos restitutivos, cuyo alcance supera la esfera jurídica del quejoso, pues los conductos de abastecimiento de agua difícilmente pueden ser instalados únicamente en el domicilio del quejoso.

\section{El caso del ingreso mínimo vital de Veracruz frente a la epidemia del covid-19}

Un profesor de una escuela particular se quedó sin trabajo el 6 de julio de 2020. Sin otra fuente de sustento, él y sus dos hijos menores de edad se han quedado sin prestaciones de seguridad social, sin ingresos y sin posibilidades de subsistencia.

En ese contexto, el profesor presentó por propio derecho y en representación legal de sus hijos, una demanda de amparo, solicitando la protección de la justicia federal,

\footnotetext{
$\overline{78}$ Juicio de amparo $325 / 2020$, suspensión de fecha 25 de junio de 2020, emitido por el Juez Cuarto de Distrito en el Estado de San Luis Potosí, p. 6.

${ }^{79}$ Idem

García-Tejeda, Enrique y Torres Checa, Daniel, “La judicialización de la política de la salud en México...”, Jurídica Ibero, año 6, julio-diciembre, 2021.
} 
reclamando, entre otros actos, la puesta en peligro de su vida y salud, así como la de sus hijos, al omitir garantizar el derecho al mínimo vital. ${ }^{80}$

El Juzgado Cuarto de Distrito en el Estado de Veracruz, reconoció el estado de vulnerabilidad de los quejosos, la especial relevancia de los actos reclamados y su impacto en el derecho a la salud, a la dignidad humana y a un mínimo vital. En relación con este último, el Juzgado menciona:

El goce del mínimo vital es un presupuesto sin el cual las coordenadas centrales de nuestro orden constitucional carecen de sentido, de tal suerte que la intersección entre la potestad estatal y el entramado de derechos y libertades fundamentales consiste en la determinación de un mínimo de subsistencia digna y autónoma protegido constitucionalmente. ${ }^{81}$

El derecho al mínimo vital no es un derecho expresamente reconocido en la Constitución o en las leyes federales, sino que se trata de una interpretación sistemática de los derechos fundamentales consagrados en la Constitución, realizada por el máximo tribunal, cuyo desarrollo jurisprudencial sostiene su existencia implícita como un presupuesto mínimo requerido por los individuos en un Estado democrático. ${ }^{82}$

Delimitando el interés que guardan los quejosos en el caso concreto, aunado a la necesidad de tutelares derechos fundamentales de especial relevancia, el Juzgado de Distrito concedió la suspensión de plano al profesor y a sus hijos, para el efecto de que las autoridades responsables "dicten las medidas urgentes, esenciales para garantizar un mínimo vital para su sobrevivencia humana y el de su familia, hasta en tanto subsista la contingencia de salud". ${ }^{83}$

\section{El caso atípico en materia de protección de la salud: el caso Mini Numa}

La comunidad Mini Numa, en el municipio de Metlatónoc, en el Estado de Guerrero, es una comunidad mixteca con uno de los más altos índices de pobreza extrema en el país. No cuenta con centros de salud y el centro hospitalario más cercano al lugar se encuentra a una hora y media de recorrido. Sin embargo, dicho centro de salud en ocasiones no contaba con disponibilidad, se encontraba cerrado o se negaba la atención, lo que resultó en un problema de salud pública. ${ }^{84}$

${ }_{80}$ Juicio de amparo 322/2020, suspensión de fecha 13 de junio de 2020 emitido por el Juez Cuarto de Distrito en el Estado de Veracruz, p. 3.

${ }^{81}$ Juicio de amparo 322/2020, suspensión de fecha 13 de junio de 2020 emitido por el Juez Cuarto de Distrito en el Estado de Veracruz, p. 4.

82 Véase Tesis 1a. XCVII/2007, Seminario Judicial de la Federación y su Gaceta, Novena Época, tomo XXV, mayo de 2007, p. 1354; bajo el rubro: Derecho Al Mínimo Vital En El Orden Constitucional Mexicano.

83 Juicio de amparo 322/2020, suspensión de fecha 13 de junio de 2020 emitido por el Juez Cuarto de Distrito en el Estado de Veracruz, p. 15.

${ }^{84}$ Gutiérrez Rivas, Rodrigo y Rivera Maldonado, Aline, "El caso 'Mini Numa': Un litigio estratégico para la justiciabili- 
Desde 2003, los habitantes de Mini Numa reclamaron la instalación de un centro de atención medica en su comunidad, sin embargo, esta petición les fue negada por la autoridad administrativa. El secretario de salud estatal argumentó que, conforme a los lineamientos establecidos en el Modelo Integrador de Atención a la Salud (MIDAS), la comunidad no cumplía con las condiciones para contar con un centro de salud propio. El Modelo señalaba que las comunidades debían contar con una población de 2,500 habitantes por núcleo básico, a una distancia de $15 \mathrm{~km}$ de recorrido al centro de salud más cercano. ${ }^{85}$

En 2007, contra la respuesta negativa de la autoridad administrativa, cinco miembros de su comunidad presentaron una demanda de amparo, solicitando la protección colectiva del derecho a la salud en la localidad. ${ }^{86}$

De esta manera, en julio de 2008, el Juzgado Séptimo de Distrito en el Estado de Guerrero dictó una sentencia favorable a la comunidad y ordenó a las autoridades que proporcionaran mobiliario, medicamentos adecuados y acondicionamientos a una casa de salud para los habitantes de la comunidad. Igualmente, ordenó la rehabilitación del centro de salud de la cabecera municipal en Metlatónoc a través de la reconstrucción de sus espacios, el suministro de insumos y la asistencia de personal médico, sin que las autoridades sanitarias puedan alegar falta de presupuesto. ${ }^{87}$

A pesar de ser una sentencia en firme, la autoridad administrativa no dio celeridad a la orden judicial y tardó casi 10 años en ser cumplida ${ }^{88}$ El caso Mini Numa es paradigmático en cuanto a la "justiciabilidad" de derechos sociales, pero también representa los mayores retos del juicio de amparo y su efectividad.

\section{Resultados y discusión de los casos presentados}

\section{Resultados}

La tabla 1 sintetiza el análisis de cada uno de los tres casos estudiados bajo la pandemia de COVID-19, y el caso atípico de Mini Numa en el apartado tercero de este documento.

dad de los derechos sociales y la no discriminación en México", Revista de la Facultad de Derecho de la Universidad Nacional Autónoma de México, 2014, p. 90, disponible en: https://revistas-colaboracion.juridicas.unam.mx/index.php/ rev-facultad-derecho mx/article/view/28901/26128.

85 Acuña, Juan Manuel, "El caso Mini Numa. Nuevos rumbos para la protección de los derechos sociales a través del juicio de amparo en México", Biblioteca Jurídica Virtual del Instituto de Investigaciones Jurídicas de la Universidad Nacional Autónoma de México, 3 de abril de 2019, disponible en: http://ru.juridicas.unam.mx/xmlui/handle/123456789/32350.

${ }^{86}$ Concretamente, el acto reclamado es: "la vulneración directa del derecho a la salud de todas las personas, contenido en el párrafo $3^{\circ}$ del artículo $4^{\circ}$ de la Constitución Mexicana y para los pueblos indígenas, en el apartado B del artículo $2^{\circ}$ " (Gutiérrez Rivas y Rivera Maldonado, op. cit., 2014).

${ }^{87}$ Gutiérrez Rivas, Rodrigo y Rivera Maldonado, Aline, op, cit., p. 102.

${ }^{88}$ Amparo indirecto 1157/2007 (sentencia del 17 de septiembre de 2017). 
Con base en la metodología expuesta en la sección respectiva, se construyó un tamiz de análisis sustentado en los modelos de diseño de políticas por etapas y el marco de corrientes múltiples. ${ }^{89}$

TABLA 1: ANÁLISIS JURÍDICO Y DE POLÍTICAS PÚBLICAS DE LOS CASOS PRESENTADOS

\begin{tabular}{|c|c|c|c|c|}
\hline $\begin{array}{l}\text { I. Características generales de } \\
\text { las resoluciones }\end{array}$ & $\begin{array}{l}\text { Medidas } \\
\text { Salud Mi- } \\
\text { choacán }\end{array}$ & $\begin{array}{c}\text { Agua en } \\
\text { San Luis } \\
\text { Potosí }\end{array}$ & $\begin{array}{l}\text { Mínimo } \\
\text { Vital en } \\
\text { Veracruz }\end{array}$ & $\begin{array}{l}\text { Mini Numa } \\
\text { Guerrero }\end{array}$ \\
\hline \multicolumn{5}{|l|}{ Derecho a la Salud } \\
\hline \multicolumn{5}{|l|}{ Durante COVID-19 } \\
\hline \multicolumn{5}{|l|}{ Deferencia Administrativa } \\
\hline \multicolumn{5}{|l|}{ Efectos colectivos } \\
\hline \multicolumn{5}{|l|}{ II. Diseño de Políticas Públicas } \\
\hline \multicolumn{5}{|l|}{ Definición del problema } \\
\hline \multicolumn{5}{|l|}{ Selección de alternativas } \\
\hline \multicolumn{5}{|l|}{ Criterios de evaluación } \\
\hline \multicolumn{5}{|l|}{ Proyección de resultados } \\
\hline \multicolumn{5}{|l|}{ Implementación } \\
\hline \multicolumn{5}{|l|}{ Evaluación } \\
\hline \multicolumn{5}{|l|}{ Precedente judicial } \\
\hline \multicolumn{5}{|l|}{ III. Marco Corrientes múltiples } \\
\hline \multicolumn{5}{|l|}{ Reafirmación valores sociales } \\
\hline Clave & Sí & & No & \\
\hline
\end{tabular}

FUENTE: Elaboración propia con información de los casos presentados en la sección anterior.

Este filtro, aplicado a cada caso, permitió estudiar las resoluciones judiciales para examinar la definición del problema por parte de los jueces, la selección de alternativas de política y en general, las características que permiten clasificar cada caso bajo la metodología ya mencionada. La construcción de la Tabla 1 permite visualizar el panorama del papel de los jueces federales en la formulación de políticas públicas de salud durante el COVID-19. Este patrón general revela los siguientes resultados y hallazgos.

\footnotetext{
$\overline{89}$ Véase la tabla 2 en el anexo 1.
} 
Los jueces que otorgan una deferencia judicial se autoexcluyen del diseño de política pública, por lo que no extienden la esfera de su actuación frente a la inacción de la autoridad administrativa. En el apartado II de la tabla 1 es posible visualizar que, en los casos de Michoacán y San Luis Potosí, no existieron alguna de las etapas o pasos de política pública que se utilizan en el diseño, al otorgar la deferencia a la administración pública.

Los casos resueltos para proteger el derecho a la salud frente a la pandemia del COVID-19 parecen no producir efectos generales en todos los casos, como en el juicio de amparo en Veracruz, donde la resolución sobre el ingreso mínimo vital sólo beneficia al quejoso. Sin embargo, en este mismo caso, el juez define un problema público: la ausencia de un ingreso, el cual no está considerado en una política de la administración pública, por lo que esta resolución es un paso hacia una mayor participación de los jueces en el diseño de políticas. No obstante, en ausencia de efectos colectivos y sin sentar un precedente judicial, esta resolución difícilmente contribuye al diseño de una política pública.

En los cuatros casos analizados existe una reafirmación de valores sociales, en lugar del análisis de un problema público y la conexión con una solución, por lo que el papel de los jueces puede explicarse de mejor forma con el marco de corrientes múltiples. En el apartado III de la tabla 1 se observa que, en todos los casos, en las resoluciones estudiadas existe la reafirmación explícita de valores sociales.

Finalmente, el caso de Mini Numa en Guerrero es atípico, ya que el juez modificó la resolución de política pública de no construir un centro de salud debido a los criterios técnicos de número de habitantes y distancia a un centro de salud: 2,500 habitantes y 15 kilómetros, respectivamente. Sin embargo, esta resolución fue más una excepción que el establecimiento de una política pública de salud: los centros de salud subsecuentes continuaron siendo construidos bajo estos parámetros técnicos de población y distancia, por lo que la resolución no parece haber logrado un cambio en la política de ubicación de los centros de salud.

\section{Discusión}

Los casos examinados sugieren que los jueces federales probablemente no participan en el diseño de las políticas públicas durante la pandemia. Las resoluciones de los juicios no incluyeron el análisis de la causa del problema, la selección de alternativas, y tampoco fijaron metas previas para la administración. Estas son etapas necesarias en un proceso del diseño de una política. ${ }^{90}$ La autoexclusión es voluntaria, puesto que en los casos con efectos colectivos sobre medidas frente al COVID-19, los jueces otorgaron una deferencia administrativa.

Para ilustrar el argumento, en el caso del juicio de amparo de San Luis Potosí, que resuelve la inacción de las autoridades municipales para proporcionar un suministro de

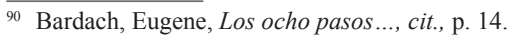
García-Tejeda, Enrique y Torres Checa, Daniel, “La judicialización de la política de la salud en México...”, Jurídica Ibero, año 6, julio-diciembre, 2021.
} 
agua potable, es posible desarrollar el siguiente escenario contrafactual para alcanzar esta conclusión.

Si el juez federal hubiera participado en el diseño de la política pública, podría haber ordenado una que estudiara al porcentaje de personas sin agua potable en la comunidad, o la relación causal entre el lavado de manos y la enfermedad provocada por el COVID-19. Este razonamiento habría "desempacado el problema público"91 y logrado una definición de problema. Además, si el juez hubiera enunciado las alternativas para la provisión de agua potable durante la pandemia, por ejemplo, un sistema de entrega de agua por medio de pipas o la entrega de paquetes de prevención de salud con gel antibacterial que atienda las recomendaciones médicas, habría definido y seleccionado opciones de política para la elección de un instrumento público que atendiera el problema. ${ }^{92}$

En este escenario hipotético, el juez podría haber proyectado resultados de las medidas ordenadas. Por ejemplo, la menor tasa de incidencia de la enfermedad provocada por el COVID-19 en la comunidad frente al promedio nacional, o el aumento de porcentaje de viviendas o personas con acceso a agua potable. ${ }^{93}$

Este contrafactual muestra el camino que seguiría la actuación de un juez federal en el diseño de una política pública, pero al no materializarse, es posible descartar el supuesto de que los jueces de las instancias analizadas participan en el diseño de aqué1las. En los casos de Michoacán y San Luis Potosí, los jueces se han limitado a reafirmar valores sociales y a otorgar la deferencia judicial a la administración pública. No parece existir una judicialización de la política de la salud frente a la pandemia del COVID-19.

Incluso en aquellos casos como el juicio de amparo en Veracruz, donde el juez definió un problema público (la ausencia de un mínimo de subsistencia) y formuló una posible solución (el otorgamiento de un ingreso mínimo vital), su resolución no parece reafirmar la existencia de un derecho colectivo, ya que los alcances de su sentencia no afectan a la colectividad, como sí lo hace la resolución sobre el suministro de agua potable en San Luis Potosí, por lo que es difícil considerar que la resolución del caso de Veracruz incide en el diseño de una política pública.

En cambio, el papel de los jueces federales en los casos examinados parece corresponder al marco de corrientes múltiples que, en un ambiente de ambigüedad y aleatoriedad, se pronuncian reafirmando valores sociales. Estos resultados son consistentes con los hallazgos de Gauri y Brinks. ${ }^{94}$ Los jueces rara vez participan en la discusión de una política pública. En muchos casos, su participación se limita a incluir el lenguaje del derecho en las discusiones públicas y ser otro espacio para el debate de la política pública.

\footnotetext{
$\overline{91}$ Bardach, Eugene, "Problems of Problem Definition in Policy Analysis", Research in Public Policy Analysis and management, 1981, pp. 161-171.

92 Young, Eóin y Quinn, Lisa, Writing effective public policy papers, Budapest, Open Society Institute, 2002, p. 58.

${ }_{93}$ Bardach, Eugene, Los ocho pasos..., cit., p. 53.

${ }^{94}$ Gauri, Varun y Brinks, Daniel M. (coords.), Courting Social Justice: Judicial Enforcement of Social and Economic Rights in the Developing World, Cambridge, Cambridge University Press, 2008, p. 304. 
No obstante, desde una concepción más amplia que el diseño de políticas públicas, la participación de los jueces puede incidir en las políticas de salud al modificar las instituciones públicas en el sector. Los cambios institucionales influyen de manera relevante en la generación de las políticas públicas, ya que el componente institucional es considerado un elemento clave en su formulación. Para algunos autores, además de incluir a las instituciones, hay otros factores que pueden explicar mejor la dinámica del proceso de las políticas como las redes, el contexto, los eventos, las ideas, los actores y la toma de decisiones. ${ }^{95}$ Aunque estos componentes no están incluidos en las etapas del diseño (policy design), sí influyen en la creación de aquéllas.

Este es el caso de la resolución T-760 que reorganizó el sistema de salud en Colombia. La Corte Constitucional modificó las instituciones de prestación del servicio al homologar los planes de salud y cambiar las reglas sobre la información que reciben los beneficiarios del sistema, entre otras medidas. ${ }^{96}$ En esta perspectiva amplia, los jueces participan en la formulación de políticas públicas al crear espacios para el diálogo y la colaboración entre actores, para analizar los cambios sustantivos en los servicios de salud. En ese sentido, la Corte Constitucional creó una forma de discutir y modificar la política de salud a favor de los beneficiarios del sistema. ${ }^{97}$

Esta participación de los tribunales en las políticas de salud no está exenta de riesgos, ya que puede afectarse la estabilidad financiera de la administración. El caso Mini Numa ordenó la construcción de un centro de salud, sin importar las restricciones presupuestales. La edificación duró casi 10 años. Este caso puede ser un antecedente de la preocupación del poder judicial de desestabilizar el presupuesto público, debido a las restricciones económicas que pueden tener las administraciones públicas: "A la Corte le da miedo impactar en la política pública". ${ }^{98}$

El problema de la inestabilidad financiera, provocada por la participación de los jueces, ha sido revisado por la literatura del derecho a la salud..$^{99}$ Ante la disyuntiva de satisfacer las necesidades de salud sin tener los recursos suficientes, se ha propuesto un proceso justo de decisión que garantice la legitimidad y equidad de dichas decisiones dentro de un marco Rawlsiano. Este proceso tiene que ser transparente, basado en razones relevantes, revisable mediante un procedimiento y exigible. ${ }^{100}$

Esta preocupación de afectar la estabilidad financiera puede explicar, en parte, el uso de la deferencia administrativa a favor de las medidas del gobierno para el cuidado de la salud ante el COVID-19, ya que los jueces evitan lidiar con las dificultades de un análisis económico extralegal. Estas razones también podrían explicar la deferencia que

\footnotetext{
${ }_{95}$ Cairney, Paul, op. cit.

96 Lamprea, Everaldo, op. cit., p. 18.3.

${ }_{97}$ Parra-Vera, Oscar y Yamin, Alicia, op. cit., p. 2645.

${ }_{98}$ Cobo, Fernanda et al., op. cit., p. 311.

99 Rid, Annette, "Book Review: Just Health: Meeting Health Needs Fairly", Bulletin of the World Health Organization, núm. 86, vol. 8, agosto de 2008, p. 653.

${ }^{100}$ Daniels, Norman, Just Health: Meeting Health Needs Fairly, Nueva York, Cambridge University Press, 2007, pp. 118-119. García-Tejeda, Enrique y Torres Checa, Daniel, “La judicialización de la política de la salud en México...”, Jurídica Ibero, año 6, julio-diciembre, 2021.
} 
se ha otorgado, por parte del Poder Judicial en México, al órgano constitucional autónomo en el mercado de las telecomunicaciones ${ }^{101} \mathrm{y}$ al Poder Legislativo en materia de política fiscal. ${ }^{102}$

\section{Limitaciones del estudio}

El número de casos analizados es insuficiente para generalizar las conclusiones de la investigación, ya que es incipiente considerar que existe una tendencia clara en la judicialización de las políticas de la salud en México, con este número reducido de juicios de amparo. Incluso los actores clave en el sector tienen opiniones divergentes sobre la participación del Poder judicial, que en ocasiones es considerado un agente de cambio, pero otros actores consideran que su participación es una intromisión ilegítima. ${ }^{103} \mathrm{En}$ futuras investigaciones que cuenten con un mayor número de juicios sobre el derecho a la salud durante la pandemia, podrán identificar posibles patrones en la participación de los jueces.

Una limitante adicional es que el uso de dos cuerpos de literatura distinta puede dificultar el análisis del problema de investigación, ya que se atiende desde dos posiciones diferentes. Por un lado, la literatura del derecho a la salud ha sido profusa en analizar la participación de los jueces en diversos países donde existe esta problemática. El enfoque de estas investigaciones ha sido el cumplimiento del derecho a la salud mediante el litigio constitucional. ${ }^{104}$ En el caso de los estudios de políticas públicas, las investigaciones incorporan temáticas adicionales y están vinculadas a la deferencia administrativa en gran parte de las investigaciones.

Aunque ambas perspectivas comparten el objeto de estudio, las investigaciones pueden no ser compatibles del todo, ya que el enfoque de los estudios de políticas se centra en los elementos extralegales de las sentencias. Esta investigación está encuadrada en este último marco, por lo que puede parecer distante a los intereses y preocupaciones principales de la literatura del derecho a la salud.

No obstante, el enfoque de derecho y políticas públicas puede aportar una perspectiva novedosa sobre un tema relevante a la luz de la pandemia de COVID-19, y tal vez servir de enlace entre los estudios de judicialización del derecho a la salud y de políticas públicas en la región. Aunque los estudios de políticas pueden parecer ajenos a nuestra tradición jurídica, cada vez surgen más obras a partir de las problemáticas y la evidencia generadas en México y Latinoamérica. ${ }^{105}$

\footnotetext{
${ }^{101}$ Tesis $1.2^{\circ}$. A.E.45 A, Seminario Judicial de la Federación, Décima Época, libro 38, febrero 2017, p. 2325; bajo el rubro: Política Regulatoria. Límites Del Escrutinio Judicial De Las Decisiones Relativas.

${ }^{102}$ Tesis 1ª/J.77/2011, Seminario Judicial de la Federación y su Gaceta, Décima Época, tomo XXXIV, agosto de 2011, p. 1341; bajo el rubro: Proporcionalidad Tributaria. El Legislador Cuenta Con Un Margen Amplo De ConfiguraCIÓn, Al Definir Las Tasas Y Tarifas.

${ }^{103}$ Cobo, Fernanda et al., op. cit., p. 308.

${ }^{104}$ Yamin, Alicia y Gloppen, Siri, op. cit.

${ }^{105}$ Sanabria-Pulido, Pablo y Rubaii, Nadia, (coords.), Policy Analysis in Colombia, Binghamton, Bristol University Press, 2020. 


\section{Conclusiones}

Los criterios de la Suprema Corte de Justicia de la Nación de los últimos años, sobre el principio de relatividad y sobre la procedencia de medidas cautelares ante la inacción de la administración pública, parecieran configurar una nueva realidad institucional, donde los jueces constitucionales tienen un margen jurídico para participar en las políticas públicas. Sin embargo, la evidencia analizada sobre las resoluciones de los jueces, a propósito de medidas de protección a la salud frente a la pandemia del COVID-19, muestra que probablemente los jueces no participan en el diseño de políticas públicas por dos razones fundamentales.

En algunos casos, el propio juez constitucional recurre al principio de deferencia judicial, lo que significa que adopta el criterio de política pública que las autoridades administrativas establecen, lo cual deja a la administración el diseño de las políticas públicas. Hay una renuncia expresa por parte del juez del análisis de elementos extralegales. En otros casos, el juez avanza hacia la definición de un problema público, y por ende, al diseño de políticas públicas, pero su resolución es limitada en este ámbito por el propio diseño institucional, por ejemplo, en el caso analizado sobre el otorgamiento de un ingreso mínimo vital de Veracruz, esto favorece sólo al quejoso y su núcleo familiar cercano. Por estas razones, el papel de los jueces está limitado al control de la actuación de la administración pública.

Sin embargo, en una perspectiva más amplia de la formulación de políticas públicas, los jueces han participado en la creación de políticas de salud en la región de Latinoamérica al modificar las instituciones. Es el caso de la Corte Constitucional de Colombia con la sentencia T-760/08, donde la Corte reorganizó el sector de salud y creó condiciones para la modificación de la política pública. ${ }^{106}$ Este caso ilustra el potencial de la intervención de los jueces en las políticas de salud, más allá del diseño de políticas públicas.

Finalmente, el número de juicios de amparo analizados es tan reducido como para identificar una tendencia de la participación de los jueces en las políticas de salud frente al COVID-19, sin embargo, estos resultados son similares a los estudios recientes sobre la participación de la Suprema Corte de Justicia de la Nación en la política de salud en México, de 2011 a 2017, donde el Máximo tribunal ha perdido la oportunidad de incidir en este sector. ${ }^{107}$ Este artículo puede contribuir a la discusión actual del papel de los jueces en las políticas de salud, cuyas investigaciones son prolijas en Latinoamérica, pero poco exploradas en México.

\footnotetext{
${ }_{106}$ Parra-Vera, Oscar y Yamin, Alicia, op. cit., p. 2592.

${ }^{107}$ Cobo, Fernanda y Charvel, Sofía, op. cit., p. 1267. 


\section{Bibliografía}

ACuÑA, Juan Manuel, "El caso Mini Numa. Nuevos rumbos para la protección de los derechos sociales a través del juicio de amparo en México", Biblioteca Jurídica Virtual del Instituto de Investigaciones Jurídicas de la UNAM, 3 de abril de 2019, disponible en: http://ru.juridicas.unam.mx/xmlui/handle/123456789/32350.

ArrietA-Gomez, Aquiles Ignacio, "Realizing the Fundamental Right to Health Through Litigation: the Colombian Case", Health and Human Rights, núm. 20, vol. 1, 2018.

BADILlo, María José, "La deferencia de los tribunales especializados en competencia económica, telecomunicaciones y radiodifusión", Tesis de licenciatura, México, CIDE, 2018, disponible en: http://hdl.handle.net/11651/2687.

BAIRD, Vanessa y JACOBI, Tonja, "Judicial Agenda Setting Through Signaling and Strategic Litigant Responses", Washington University Journal of Law \& Policy, núm. 29, 2009.

BARDACH, Eugene, "Problems of Problem Definition in Policy Analysis", Research in Public Policy Analysis and management, 1981.

BARDACH, Eugene, Los ocho pasos para el análisis de Politicas Públicas, un manual para la práctica, México, CIDE, 2001.

BIEHL, João et al., "The Judicialization of Health and the Quest for State Accountability: Evidence from 1,262 Lawsuits for Access to Medicines in Southern Brazil”, Health and Human Rights, núm. 18, vol. 1, 2016.

Bork, Robert H., The Tempting of America, New York, Free Press, 1997.

CAIrney, Paul, Understanding Public Policy, Red Globe Press, 2012.

CAIRnEY, Paul y Jones, Michael D., "Kingdon's Multiple Streams Approach: What Is the Empirical Impact of this Universal Theory?", Policy Studies Journal, núm. 44, vol. 1, 2016.

CElis Quintal, Marcos Alejandro, "El papel del Poder Judicial en el esquema de división de poderes de las entidades federativas", Biblioteca del Instituto de Investigaciones Jurídicas de la UNAM, UNAM, Instituto de Investigaciones Jurídicas, 2005, disponible en: https://archivos.juridicas.unam.mx/www/bjv/libros/4/1784/18.pdf.

CoBo, Fernanda y Charvel, Sofía, "Mexican Apex Judiciary and its Multiple Interpretations: Challenges for the Constitutional Right to Health", International Journal of Constitutional Law, vol. 18, núm. 4, 2020, disponible en: https://academic.oup. com/icon/article-abstract/18/4/1254/6077862.

Сово, Fernanda et al., "La judicialización del derecho a la protección de la salud desde la óptica de los actores clave", Salud Pública de México, núm. 63, vol. 2, marzoabril de 2021.

Daniels, Norman, Just Health: Meeting Health Needs Fairly, Nueva York, Cambridge University Press, 2007.

Dunn, William N., Public Policy Analysis, Estados Unidos, Routledge, 2015. 
Franco talamantes, Amadeo, "Neil Gorsuch y el futuro del derecho administrativo", Revista Nexos, 10 de mayo de 2017, disponible en: https://eljuegodelacorte.nexos. com. $m x / ? p=6580 \#$ ftn6.

GAURI, Varun y BRInKs, Daniel M. (coords.), Courting Social Justice: Judicial Enforcement of Social and Economic Rights in the Developing World, Cambridge, Cambridge University Press, 2008.

GutiÉRrez rivas, Rodrigo y Rivera Maldonado, Aline, “El caso 'Mini Numa': Un litigio estratégico para la justiciabilidad de los derechos sociales y la no discriminación en México", Revista de la Facultad de Derecho de la Universidad Nacional Autónoma de México, 2014, p. 90, disponible en: https://revistas-colaboracion. juridicas.unam.mx/index.php/rev-facultad-derecho mx/article/view/28901/26128.

Hoffmann, Florian y Bentes, Fernando R.N.M., Accountability for Social and Economic Rights in Brazil, Cambridge, Cambridge University Press, 2008.

Hood, Christopher, The Tools of Government, Nueva Jersey, Chatham House Publishers, 1984.

Howlett, Michael et al., "From Tools to Toolkits in Policy Design Studies: the New Design Orientation Towards Policy Formulation Research", Policy \& Politics, núm. 43, vol. 2, abril de 2015, disponible en: https://www.researchgate.net/publication/275719874_From_tools_to_toolkits_in_policy_design_studies_The_new_ design_orientation_towards_policy_formulation_research.

JARAMILlo, Luis Eduardo y PACHÓN, Mónica, "Control de constitucionalidad abstracto y sus implicaciones en las políticas públicas: el caso de la descentralización fiscal en Colombia", Universidad de los Andes, Escuela de Gobierno Alberto Lleras Camargo, Bogotá, julio 2019, disponible en: https://egob.uniandes.edu.co/images/books/ DT/DT-64.pdf.

Kirschen, Etienne Said, Economic Policy in Our Time, Ámsterdam, North-Holland Publishing, 1964.

KNOTT, Jack H., "Policy Change and Deregulation: Explaining Differences in Legislative Outcomes", Policy Currents, núm. 3, vol. 1, 1993.

LAmPreA, Everaldo, "The Judicialization of Health Care: A Global South Perspective", Annual Review of Law and Social Science, núm. 13, 2017.

LANDAU, David, "The Reality of Social Rights Enforcement", Harvard International Law Journal, núm. 53, 2012.

Lasswell, Harold, “The Policy Orientation”, en Lerner, Daniel y LASSwell, Harold (eds.), The Policy Sciences, Standford, Stanford University Press, 1951.

Leigh, Tara, "Book Review: The Supreme Court's Legytmacy Dilemma", Harvard Law Review, 2019, disponible en: https://harvardlawreview.org/wp-content/ uploads/2019/06/2240-2276_Online.pdf.

Macdonald, Douglas, "Coerciveness and the Selection of Environmental Policy Instruments”, Canadian Public Administration, núm. 44, vol. 2, 2001. 
Martínez Estay, José Ignacio, “Auto-Restricción, Deferencia y Margen de Apreciación. Breve Análisis de sus orígenes y de su desarrollo", Centro de Estudios Constitucionales de Chile, Universidad de Talca, Chile, año 12, núm. 1, 2014, disponible en: https://scielo.conicyt.cl/pdf/estconst/v12n1/art09.pdf.

McKeEVer, Robert J., Raw Judicial Power?: The Supreme Court and American Society, Manchester, Manchester University Press, 1993.

Merino, Mauricio, Políticas públicas. Ensayo sobre la intervención del Estado en la solución de problemas públicos, CIDE, México, 2013.

Motta Ferraz, Octávio Luiz, "Health in the Courts of Latin America", Health and Human Rights, núm. 20, vol. 1, 2018, disponible en: https://www.ncbi.nlm.nih.gov/ pmc/articles/PMC6039732/.

PARRA-VERA, Oscar y YAMIN, Alicia, "La sentencia T-760 de 2008, su implementación e impacto: Retos y oportunidades para la justicia dialógica", Tratado de derecho a la salud, Argentina, Abeledo Perrot, 2013.

Peters, B. Guy, Advanced introduction to public policy, University of Pittsburg, 2015.

Peters, B. Guy y Zittoun, Philippe, Contemporary Approaches to Public Policy, Theories, Controversies, and Perspectives, Londres, Palgrave Macmillan, 2016.

Rabkin, Jeremy A., Judicial Compulsions: How Public Law Distorts Public Policy, New York, Basic Books, 1989.

RID, Annette, "Book Review: Just Health: Meeting Health Needs Fairly", Bulletin of the World Health Organization, núm. 86, vol. 8, agosto de 2008.

SABATIER, Paul A., Teorías del proceso de las políticas públicas, Buenos Aires, Westview Press, 2010.

Sanabria-Pulido, Pablo y Rubait, Nadia, (coords.), Policy Analysis in Colombia, Binghamton, Bristol University Press, 2020.

Tale, Neal y Vallinder, Torbjorn, The Global Expansion of Judicial Power, Nueva York, New York University Press, 1997.

Young, Eóin y QuINN, Lisa, Writing effective public policy papers, Budapest, Open Society Institute, 2002.

Ventura Rodríguez, Manuel Enrique, "La deferencia a favor de las Administraciones públicas en el Derecho Administrativo Contemporáneo", Estudios Jurídicos sobre Administración Pública, Posgrado de la Universidad Nacional Autónoma de México, México, 2012, disponible en: http://derecho.posgrado.unam.mx/congresos/ ivci_vmda/ponencias/ManuelVentura.pdf.

ZAHARIADIs, Nikolaos, Bounded Rationality and Garbage Can Models of Policy-Making, Londres, Palgrave Macmillan, 2016. 


\section{ANEXO 1}

TABLA 2. Tamiz de análisis con base en la metodología expuesta en el apartado 2

1. ¿El juez definió el problema público?
$\begin{aligned} & \text { 2. ¿El juez eligió un instrumento distinto a la actividad realizada hasta ese mo- } \\ & \text { mento por la administración pública? }\end{aligned}$

3. Si el juez estableció un instrumento obligatorio para la administración pública, ¿el juez escogió libremente la alternativa, después de enumerar varias opciones?

4. Si el juez estableció un instrumento obligatorio para la administración pública, ¿el juez solo concedió la razón al quejoso al establecer la acción solicitada por el actor, sin contemplar alguna alternativa?

5. Si el juez estableció un instrumento obligatorio para la administración pública, ¿el juez invocó alguna tesis de jurisprudencia para sustentar su resolución sobre cómo debía actuar el gobierno?

6. Si el juez estableció un instrumento obligatorio, ¿la obligación establecida por el juez a la autoridad administrativa tiene una conexión directa con la definición del problema público?

7. Si el juez estableció un instrumento obligatorio, ¿estableció un parámetro objetivo de cumplimiento de su resolución para la administración pública?

8. ¿El juez ordenó alguna medida de implementación o procedimiento específico a la administración pública para el cumplimiento de su resolución?

9. En el caso analizado, ¿el juez motivó y fundamentó su resolución exclusivamente con aspectos normativos, como la protección del derecho de la salud?

10. En el caso analizado, además de que el juez motivara y fundamenta su resolución con aspectos normativos, como la protección del derecho de la salud, ¿el juez usó cifras sobre tasa de enfermedad o utilizó algún otro argumento técnico cuantificable para soportar su resolución?

11. ¿El juez invocó el principio de deferencia administrativa?

12. ¿El juez analizó o evaluó las políticas públicas de salud de la administración pública para emitir su resolución? 